\title{
Replacement of mitral valve in active infective endocarditis
}

\author{
Magdi Yacoub, Lucio Pennacchio, Donald Ross, and Lawson McDonald \\ From the National Heart Hospital, London
}

Infective endocarditis which is resistant to medical treatment is fatal. In a woman of 32 years the mitral valve was replaced, in the presence of active infection, by a fascia lata valve. Her postoperative course was entirely satisfactory. Twelve months after operation, after a normal full-term pregnancy, she gave birth to healthy twins. The place of valvar replacement in the treatment of active infective endocarditis of the mitral valve is discussed.

The majority of patients with infective endocarditis respond satisfactorily to antibiotic treatment. Some develop severe valvar regurgitation, and others resistant infection or repeated embolism. In such patients excision of the infected valve and correction of the haemodynamic lesion during the active stage may be indicated (Yeh, Hall, and Ellison, 1964; Branniff, Shumway, and Harrison, 1967; Hurley, Eldridge, and Hultgren, 1967; Kretschmer and Lawrence, 1969; Cleland et al., 1969). In most of the reported patients, in whom operation was performed, the aortic valve was infected (Wallace, Young, and Osterhout, 1965; Kaiser et al., 1967; McDonald, 1967; Scott, Fish, and Crutcher, 1967). In only 4 reported patients was the mitral valve the site of infection (Robicsek et al., 1967; Wilcox et al., 1967; Windsor and Shanahan, 1967). This report describes a patient with resistant active bacterial endocarditis of the mitral valve, who was treated by valvar replacement, using a fascia lata valve. The value and risks of valvar replacement in acute infective endocarditis are discussed.

\section{Case report}

The patient was a woman of 32 years who had had rheumatic fever at the age of 13 , and was seen in August 1969. After a miscarriage, in October 1968, she became febrile and there was clinical and laboratory evidence of infective endocarditis. A Streptococcus pyogenes was grown from her blood. Antibiotic treatment was begun early in the illness but the patient discharged herself from hospital and, on and off, since that time had had recurrent clinical evidence of infective endocarditis. Furthermore, there had been several episodes of systemic embolism, including one to the right femoral artery on 29 May. On 6 August she presented with abdominal pain and jaundice.

On examination she was jaundiced and overweight. The arterial pulses were irregular, and of full volume, and blood pressure was $120 / 80$ mmHg. The jugular venous pressure and pulse were normal, and the cardiac impulse impalpable. On auscultation, in the mitral area, the first heart sound was slightly accentuated and followed by a moderate mitral pansystolic murmur. In diastole there was a faint and fairly late opening snap of the mitral valve and a left ventricular third heart sound followed by a diastolic murmur of moderate intensity and length. In the aortic area there was a faint ejection systolic murmur with normal first and second heart sounds. There were basal crepitations which cleared with coughing and the liver was one finger's breadth enlarged. Electrocardiogram in August 1969 showed atrial fibrillation; previously there had been right axis deviation and evidence of moderate left atrial hypertrophy. $X$-rays showed moderate enlargement of the ventricular mass and slight to moderate left and right atrial enlargement, with slight prominence of the pulmonary artery and no pulmonary venous congestion. The urine contained neither albumin nor sugar. Blood counts showed a polymorphonuclear leucocytosis and raised sedimentation rate, without significant anaemia.

Thus, there was evidence of rheumatic heart disease with mitral valvar disease, in which the lesion was mixed with regurgitation and stenosis, and of infective endocarditis, which was and remained resistant to antibiotic therapy. The infective endocarditis was not controlled by a further course of intensive antibiotic treatment, and further systemic emboli occurred, and the heart 


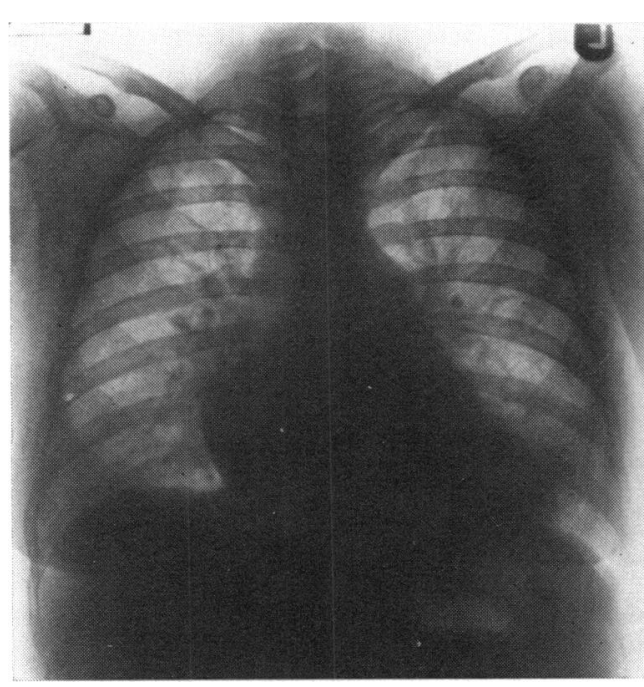

FIG. I Chest x-ray on 14 October 1969, showing moderate enlargement of the heart and pulmonary artery, also pulmonary venous congestion. See text.

remained enlarged (Fig. I). Replacement of the mitral valve was therefore undertaken in October 1969. This was performed through a median sternotomy. The external appearances of the heart were consistent with moderately severe mitral regurgitation. The left atrial mean pressure measured at operation, before starting cardiopulmonary bypass, was $15 \mathrm{mmHg}$ with a $\mathrm{V}$ wave of $38 \mathrm{mmHg}$. There was no gradient across the aortic valve. Normothermic bypass was established with arterial return to the ascending aorta. The left atrium was opened behind Sondesgaard's sulcus. The mitral valve was thickened and looked stenotic and regurgitant with an opening measuring $\mathrm{r} \cdot 8 \mathrm{~cm}$ in length. There was a soft vegetation on the atrial surface of the aortic cusp. The chordae tendineae were fused into two columns of fibrous tissue. The valve was excised and replaced by an autogenous fascia lata valve fixed to a frame measuring $26 \mathrm{~mm}$ in diameter (Ionescu and Ross, 1969). After getting rid of air, bypass was discontinued. The postoperative recovery was rapid and uncomplicated. A chest $x$-ray on 9 March 1970 (Fig. 2) showed a reduction in the size of the heart and pulmonary artery, and no pulmonary venous congestion. Twelve months after operation the patient was safely delivered of twins, after a normal term pregnancy.

\section{Discussion}

The use of antibiotics has favourably influenced the prognosis of patients suffering from bacterial endocarditis with a reduction in the immediate mortality rate (Hickie, 196I ; Robinson and Ruedy, 1962). Destruction of the valve resulting in severe heart

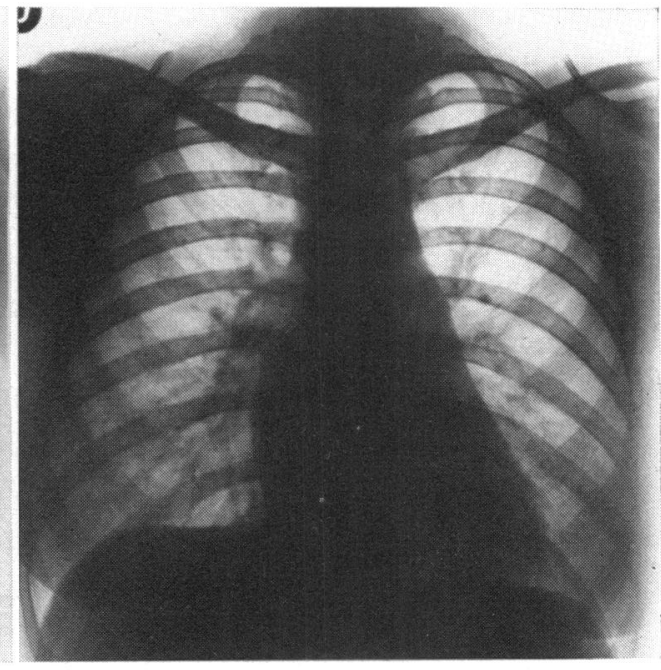

FIG. 2 Chest $x$-ray on 9 March 1970. The heart and pulmonary artery are smaller than in Fig. I and the pulmonary veins are not congested. See text.

failure, the presence of resistant infection, and repeated systemic embolism may be regarded as indications for valvar replacement. In 279 patients with infective endocarditis who were seen between 1950 and 1960, Hickie (I96I) found that the commonest cause of death was cardiac failure. It occurred in 60 patients, and in a further 54, vegetations leading to systemic emboli (43 patients), coronary emboli (Io patients), and valvar stenosis (I patient) were the cause of death.

The value of valvar replacement during the active stage of infective endocarditis has recently been stressed (Kretschmer and Lawrence, 1969). In most of the reported patients, the aortic valve was the site of the infection (Yeh et al., 1964; Wallace et al., 1965; Branniff et al., 1967; Hurley et al., 1967; Kaiser et al., 1967; McDonald, 1967; Scott et al., 1967). In contrast, the mitral valve was involved in only 4 reported cases (Robicsek et al., 1967; Wilcox et al., 1967; Windsor and Shanahan, 1967). The risks of dissemination or recurrence of the infection, or rupture of a mycotic aneurysm during or after the operation, have been slight. In the patient described here, a fascia lata graft (Ionescu and Ross, 1969) was used because autogenous tissues are believed to be more resistant to infection, and also to avoid the risk of longterm anticoagulant treatment in a woman in the childbearing age. Her successful pregnancy and the birth of twins indicate a satisfactory operative result. 


\section{References}

Branniff, B. A., Shumway, N. E., and Harrison, D. C. (1967). Valve replacement in active bacterial endocarditis. New England fournal of Medicine, 276, 1464 .

Cleland, W., Goodwin, J., McDonald, L., and Ross, D. (1969). Medical and Surgical Cardiology, p. 245. Blackwell Scientific Publications, Oxford and Edinburgh.

Hickie, J. B. (196I). Bacterial endocarditis in Sydney, 1950-1959. Medical fournal of Australia, 1, 929.

Hurley, E. J., Eldridge, F. L., and Hultgren, H. N. (1967). Emergency replacement of valves in endocarditis. American Heart fournal, 73, 798.

Ionescu, M., and Ross, D. N. (1969). Heart valve replacement with autologous fascia lata. Lancet, 2, 335 .

Kaiser, G. C., Willman, V. L., Thurmann, M., and Hanlon, C. R. (1967). Valve replacement in cases of aortic insufficiency due to active endocarditis. fournal of Thoracic and Cardiovascular Surgery, 54, 491.

Kretschmer, K. P., and Lawrence, G. H. (1969). Valve replacement in patients with bacterial endocarditis. American fournal of Surgery, 118, 273.

McDonald, L. (1967). Natural history and indications for surgery in aortic valvar disease. Proceedings of the Royal Society of Medicine, 60, I015.

Robicsek, F., Payne, R. B., Daugherty, H. K., and Sanger, P. W. (1967). Bacterial endocarditis of the mitral valve treated by excision and replacement. Annals of Surgery, 166, 854.

Robinson, M. J., and Ruedy, J. (1962). Sequelae of bacterial endocarditis. American fournal of Medicine, 32, 922.

Scott, S. M., Fish, R. G., and Crutcher, J. C. (1967). Early surgical intervention for aortic insufficiency due to bacterial endocarditis. Annals of Thoracic Surgery, 3, 158.

Wallace, A. G., Young, W. G., and Osterhout, S. (1965). Treatment of acute bacterial endocarditis by valve excision and replacement. Circulation, 3I, 450.

Wilcox, B. R., Proctor, H. J., Rackley, C. E., and Peters, R. M. (1967). E $x$ rly surgical treatment of valvular endocarditis. Fournal of the American Medical Association, 200, 820.

Windsor, H. M., and Shanahan, M. (1967). Emergency valve replacement in bacterial endocarditis. Thorax, 22, 25.

Yeh, T. J., Hall, D. P., and Ellison, R. G. (1964). Surgical treatment of aortic valve perforation due to bacterial endocarditis: a report of six cases. American Surgeon, 30, 766.

Requests for reprints to Dr. Lawson McDonald, National Heart Hospital, Westmoreland Street, London WIM 8BA.

\section{Symposium on Platelets, Drugs, and Thrombosis}

The above symposium is to be held $16-18$ October, 1972, at McMaster University Medical Centre, Hamilton, Ontario, Canada. The symposium is sponsored by the Faculty of Medicine, McMaster University, the Ontario Heart Foundation, and the Canadian Heart Foundation. Thirty-six internationally respected investigators have agreed to present papers. There will be a fee of $\$ 30$ for registration and the total attendance will be limited to 300 so that discussion will be possible and profitable.

Further information can be obtained from Ontario Heart Foundation, 247 Davenport Road, Toronto I80, Canada. 